Research Article

\title{
Relationship of coronary collateral development with mean arterial pressure in patients with stable coronary artery disease
}

\author{
Asli Kurtar Mansiroglu, Isa Sincer \\ Bolu Abant Izzet Baysal University Hospital, Department of Cardiology, Bolu, Turkey
}

ABSTRACT

Aims: The prognostic value of blood pressure and the association between these parameters and cardiovascular conditions have been established in literature. In this study, we aimed to investigate the correlation between peripheral blood pressure parameters with degree of coronary collateral development (CCD) in stable coronary artery disease (CAD) subjects with established critical artery stenosis.

Methods: A total of 363 patients with stable angina pectoris undergoing coronary arteriography were enrolled and divided on the basis of the development of CCD into two groups: group with adequate CCD $(n=120)$ and group with inadequate CCD $(n=243)$. Peripheral blood pressure parameters were evaluated before coronary arteriography.

Results: Peripheral diastolic blood pressure (DBP) and mean arterial pressure (MAP) levels were significantly higher in the inadequate CCC group ( $81.5 \pm 10.7$ vs $77.9 \pm 9.9, p=0.02$ and $100.6 \pm 11.8$ vs $96.6 \pm 9.3, p<0.001)$. In Pearson's correlation analysis revealed that, Peripheral DBP and MAP levels were significantly correlated with Rentrope Collateral Grading $(\mathrm{r}=0.26, p<0.003$ and $\mathrm{r}=0.29$, $p<0.001$, respectively). ROC curve analysis of MAP and DBP for prediction of inadequate. At the cut-off value of $>99,8 \mathrm{mmHG}$, sensitivity and specificity of MAP were $57 \%$ and $69 \%$, respectively. At the cut-off value of $>79,5 \mathrm{mmHg}$, sensitivity and specificity of DBP were $72 \%$ and $42 \%$, respectively.

Conclusion: The present study suggests that peripheral DBP and MAP levels may be associated with degree of collateral development in chronic stable CAD. Low peripheral DBP and MAP in the case of severe coronary stenosis in stable CAD may be an important stimulus for coronary collateral development.

Keywords: Coronary collateral development; stable coronary artery disease; peripheral mean arterial pressure.

Copyright (C) 2018 experimentalbiomedicalresearch.com

Corresponding Author: Dr. Isa Sincer,

Abant Izzet Baysal University Hospital,

Department of Cardiology, Golkoy, 14280,

Bolu, Turkey

Email: isasincer@yahoo.com
ORCID ID: https://orcid.org/0000-0003-2399-9585

Received 2018-08-09, Revisions 2018-09-15

Accepted 2018-09-17

Publication Date 2018-10-01 


\section{Introduction}

The support of coronary collaterals for affected myocardial area due to ischemia has long been known. Ventricular functions, infarct size and aneurysm formation are positively affected by well-developed coronary collateral vessels [17] . The presence of factors such as proximal stenosis, severity of stenosis, duration of angina pectoris, male sex, low heart rate, total cholesterol, and triglyceride level have been shown in many studies when considering the factors affecting the formation of collateral circulation $[8,9]$. It has been shown that there is a direct and independent relationship between coronary artery disease and blood pressure [10].

Steady and pulsatile components of blood pressure are mean arterial pressure (MAP) and pulse pressure (PP) respectively. Peripheral vascular resistance and ventricular ejection together determine the MAP [11]. Mean arterial pressure and diastolic blood pressure, systolic blood pressure and pulse pressure are not absolutely reliable in estimating central blood pressure values [12].

Diastolic arterial pressure remains constant from the aorta to the periphery while the systolic arterial pressure and pulse pressure increases from the aorta to the periphery in young healthy people [12]. The increase in pulse pressure may be physiological (such as age, body weight, heart rate, sex) or pathological (such as changes in vasomotor tone, arterial stiffness) [13]. The distinction between the two components of blood pressure is clinically relevant because recent findings have shown that pulse pressure is more sensitive to evaluate cardiovascular risks than DBP, SBP, and MAP [13]. Few studies have shown the effect of MAP on cardiovascular diseases [14,15]. In the 4 Chicago epidemiological studies, Dyer et al. showed that the steady component of the blood pressure (highly correlated with MAP) is even stronger with respect to cardiovascular diseases than pulse pressure [16]. MAP gives the mean perfusion pressure measurements of the systemic circulation. Changes in MAP can be explained by the combination of systemic vascular resistance (SVR), heart rate and mean right atrial pressure (mRAP) interaction. MAP autoregulation is the most important feature of cardiovascular system. Acute falls in MAP are met with systemic arterial vasoconstriction, increases in pulse volumes (via venocontraction and positive inotropes) and sympathetic system effects [12]. Different levels of critical blood among the organs may be due to different factors such as previous hypertension history, vasoactive therapy, and age. Although there is no significant low value for MAP, the recommended value for organ hypoperfusion in septic shock guidelines is above $65 \mathrm{~mm} \mathrm{Hg} \mathrm{[17].} \mathrm{On} \mathrm{the} \mathrm{other} \mathrm{hand,}$ when MAP is above $85 \mathrm{mmHg}$, regional perfusion and tissue oxygenation do not cause a problem [18].

We would like to investigate the relationship between mean arterial pressure [(diastolic blood pressure + (systolic blood pressuresystolic diastolic blood pressure / 3)] and diastolic blood pressure and CCD development in the present study.

\section{Methods}

Three hundred sixty three (259 males, 104 females) patients who had undergone coronary angiography in our institution between March 2015 and February 2018 were included to the study. Of these patients, clinical, laboratory and angiographic data were analyzed. Patients who had at least $95 \%$ luminal narrowing in at least one major epicardial coronary artery were included. Age, gender, body weight, 
comorbidities such as diabetes mellitus and hypertension, smoking habit and medication on use were obtained from the patient files. Laboratory data; serum cholesterol and glucose levels, hemogram were also noted. If the subjects received antihypertensive drug or systolic or diastolic blood pressure of the participants were higher than $140 \mathrm{mmHg}$ or 90 $\mathrm{mmHg}$, then they have been considered as hypertensive. Current use of antidiabetic medication or a fasting glucose level above $126 \mathrm{mg} / \mathrm{dl}$ make the diagnosis of diabetes mellitus. Hyperlipidemia was defined as total cholesterol higher than $200 \mathrm{mg} / \mathrm{dl}$ or triglyceride higher than $150 \mathrm{mg} / \mathrm{dl}$. Exclusion criteria were as follows: a recent (within 6 months) history of acute coronary syndrome, atrial fibrillation, primary valvular disease, decompensated heart failure, previous coronary artery stenting or bypass operation, congenital heart disease, idiopathic dilated or hypertrophic cardiomyopathy, recent history of blood transfusion, severe hepatic diseases, pregnancy, septicemia, the presence of coexistent inflammatory disease (e.g. rheumatoid arthritis), thrombocytopenia, renal failure and malignancy. The study was approved by the Local Ethics Committee of the institution.

\section{Laboratory data}

Peripheral venous blood samples were drawn from stable CAD patients who were accepted for angiography or during regular follow-up checkups. Serum glucose, creatinine, total cholesterol, high-density lipoprotein cholesterol, and low-density lipoprotein cholesterol were measured using an automatic biochemical analyzer (Architect C8000, USA). Complete blood count was determined using simultaneous optical and impedance measurements (Cell Dyn 3700; Abbott Diagnostics, Lake Forest, Illinois, USA).

\section{Blood Pressure Measurements}

The conventional peripheral blood pressure measurements were obtained with invasive blood pressure measurements using a sphygmomanometer (Clinical Guard BP-1305 Blood Pressure Monitor, Hangzhou Sejoy Co Ltd, Germany) from right arm. Blood pressure (BP) was measured by using a standard mercury sphygmomanometer with a cuff size adapted to the patient's arm circumference applied to the upper non-dominant arm at heart level. The measurements were taken 3 times and the average of the last 2 measurements was calculated. Brachial pulse pressure definition was calculated as brachial systolic and diastolic blood pressure difference. For practical purposes, an approximation to MAP can be obtained by applying the following simple equation Mean Arterial Pressure= Diastolic Pressure $+(1 / 3 \times$ Pulse Pressure $)$ [19] Smoking, drinks with caffeine and alcohol consumption were banned for 24 hours prior to measurements.

\section{Coronary angiography evaluation}

Femoral or radial artery access by using Seldinger technique were done in coronary angiographies. More than $95 \%$ of epicardial coronary stenosis of cases were included to the study. Rentrop classification was applied to determine coronary collateral rating [8].

According to this classification; Grade 0 refers to lack of filling in collateral vessels, Grade 1 refers to filling in side branches via collateral channels without visualization of the epicardial artery, Grade 2 refers to partial filling in the epicardial major coronary artery via collateral channels, and Grade 3 refers to complete filling in the epicardial major coronary artery. The coronary angiograms were interpreted by three interventional cardiologists who were blinded to the clinical, laboratory and demographic data of the patients. When more 
than one vessel met the predefined criteria, the CCD with the highest Rentrop grade was used for analysis. The patients were classified as inadequate CCD (Rentrop grades 0-1) and the adequte CCD (Rentrop grades 2-3) groups.

We also measured the Gensini score of each participant from the angiography recordings. According to the degree of luminal narrowing and its geographic significance, a severity index assigned for each coronary stenosis to make the Gensini score [20].

\section{Statistical analysis}

Statistical analysis were conducted with SPSS software (SPSS 16.0 for Windows, IBM Co, Chicago, IL, USA). Distribution of the variables in study groups were analyzed by Kolmogorov-Smirnov test. Normal distributed variables were compared by $\mathrm{t}$ test and expressed as mean \pm standard deviation. Variables that without normal distribution were compared with Mann Whitney U test and expressed as median (interquartile range). Chisquare test used in comparison of nonparametric variables between study groups. Diagnostic ability of diastolic blood pressure and MAP to detect inadequate CCD was evaluated with receiver operating characteristic curves (ROC). All results were considered statistically significant at the level of $p<0.05$.

\section{Results}

Of the study population $243(67 \%)$ patients had inadequate CCD and 120 (33\%) had adequate CCD. Baseline patient demographics, including age, sex and clinical risk factors, were similar between the groups, except that the current smoking rate was mildly lower in the inadequate CCD group $(30 \%$ vs $41 \%$, $\mathrm{p}=0.043$ ). Previous medications were also comparable between the two groups (Table 1).
Table 1. General characteristics of the study groups.

\begin{tabular}{|c|c|c|c|}
\hline $\begin{array}{l}\text { Baseline } \\
\text { characteristics }\end{array}$ & $\begin{array}{l}\text { Inadequate } \\
\text { CCD } \\
(n=243)\end{array}$ & $\begin{array}{l}\text { Adequate } \\
\text { CCD } \\
(n=120)\end{array}$ & $p$ \\
\hline $\begin{array}{l}\text { Age }(\text { mean } \pm \text { SD) } \\
(\text { years }))\end{array}$ & $62 \pm 10$ & $67 \pm 10$ & 0.051 \\
\hline $\begin{array}{l}\text { Body mass index } \\
(\mathrm{kg} / \mathrm{m} 2)\end{array}$ & $27.5 \pm 4.1$ & $26.2 \pm 4.7$ & 0.465 \\
\hline Male/female & $164 / 79$ & $95 / 25$ & 0.021 \\
\hline Hypertension (\%) & $151(62 \%)$ & $78(65 \%)$ & 0.644 \\
\hline Smoking & $62(29,8 \%)$ & $43(40,9 \%)$ & 0.043 \\
\hline Family history & $243(13 \%)$ & $10(9 \%)$ & 0.210 \\
\hline Diabetes mellitus & $99(41 \%)$ & $45(37 \%)$ & 0.211 \\
\hline Acetyl salicylate & $142(58 \%)$ & $64(53 \%)$ & 0.356 \\
\hline Clopidogrel & $28(11 \%)$ & $15(12 \%)$ & 0.786 \\
\hline Statin & $41(17 \%)$ & $24(\% 20)$ & 0,160 \\
\hline $\begin{array}{l}\text { Calcium channel } \\
\text { blocker }\end{array}$ & $50(21 \%)$ & $24(25 \%)$ & 0.078 \\
\hline ACE inhibitor & $63(25 \%)$ & $25(21 \%)$ & 0.287 \\
\hline ARB & $60(25 \%)$ & $25(21 \%)$ & 0.182 \\
\hline B-blocker & $113(\% 46)$ & $58(48 \%)$ & 0.742 \\
\hline
\end{tabular}

CCD: Coronary collateral development. ACE: angiotensin-converting enzyme. ARB: angiotensin receptor blocker. SD: standard deviation.

Most of the serum biochemistry of the subjects in inadequate and adequate CCD groups were not statistically different, however, compared to inadequate $\mathrm{CCD}$ group LDL-cholesterol $(p=0.02)$ were significantly higher in adequate CCD group (Table 2).

There was no significant difference between the two groups in terms of hemoglobin and platelet count. Peripheral DBP and MAP levels were significantly higher in the inadequate CCD group $(81.5 \pm 10.7$ vs $77.9 \pm 9.9 p=0.02$ and $100.6 \pm 11.8$ vs $96.6 \pm 9.3<.001$ ) (Table 3 ). In 
Pearson's correlation analysis revealed that, Peripheral DBP and MAP levels were significantly correlated with Rentrope Collateral Grading $(\mathrm{r}=0.26, p<0.003$ and $\mathrm{r}=0.29, p<0.001$, respectively)

Table: 2. Laboratory data of the study cohort.

\begin{tabular}{|l|l|l|l|}
\hline Parameters & $\begin{array}{l}\text { Inadequate } \\
\text { CCD }(\mathbf{n}=\mathbf{2 4 3})\end{array}$ & $\begin{array}{l}\text { Adequate } \\
\text { CCD } \\
\text { (n=120) }\end{array}$ & $p$ \\
\hline $\begin{array}{l}\text { Creatinine } \\
\text { (mg/dl) }\end{array}$ & $0.95 \pm 0.23$ & $0.95 \pm 0.25$ & 0.843 \\
\hline $\begin{array}{l}\text { Fasting plasma } \\
\text { glucose (mg/dl) }\end{array}$ & $122 \pm 50$ & $125 \pm 45$ & 0.067 \\
\hline $\begin{array}{l}\text { LDL-cholesterol } \\
\text { (mg/dl) }\end{array}$ & $116 \pm 39$ & $120 \pm 41$ & 0.020 \\
\hline $\begin{array}{l}\text { HDL-cholesterol } \\
\text { (mg/dl) }\end{array}$ & $41 \pm 10$ & $42 \pm 10$ & 0.904 \\
\hline $\begin{array}{l}\text { Triglyceride } \\
\text { (mg/dl) }\end{array}$ & $181 \pm 111$ & $172 \pm 136$ & 0.061 \\
\hline $\begin{array}{l}\text { Total cholesterol } \\
\text { (mg/dl) }\end{array}$ & $184 \pm 41$ & $188 \pm 48$ & 0.248 \\
\hline $\begin{array}{l}\text { Hemoglobin } \\
\text { (gr/dl) }\end{array}$ & $14 \pm 1,8$ & $14 \pm 1,5$ & 0.257 \\
\hline $\begin{array}{l}\text { Platelet counts } \\
\text { (k/mm }{ }^{3} \text { ) }\end{array}$ & $239 \pm 56$ & $233 \pm 60$ & 0.224 \\
\hline Angiography & $43.3 \pm 36.8$ & $66 \pm 29$ & $<.001$ \\
\hline Gensini score & & \\
\hline
\end{tabular}

Table 3. Peripheral blood pressure findings.

\begin{tabular}{|l|l|l|l|}
\hline $\begin{array}{l}\text { Hemodynamic } \\
\text { detection }\end{array}$ & $\begin{array}{l}\text { Inadequate } \\
\text { CCD }(\mathbf{n}= \\
\mathbf{2 4 3})\end{array}$ & $\begin{array}{l}\text { Adequate } \\
\text { CCD } \\
(\mathbf{n = 1 2 0})\end{array}$ & $\boldsymbol{p}$ \\
\hline Heart rate, beat/min & $74 \pm 10$ & $76 \pm 11$ & 0.157 \\
\hline $\begin{array}{l}\text { Peripheral systolic BP } \\
\text { (mm Hg) }\end{array}$ & $138 \pm 18$ & $135 \pm 12$ & 0.056 \\
\hline $\begin{array}{l}\text { Peripheral diastolic BP } \\
\text { (mm Hg) }\end{array}$ & $81.5 \pm 10.7$ & $77.9 \pm 9.9$ & 0.020 \\
\hline $\begin{array}{l}\text { Pulse pressure } \\
\text { (mmHg) }\end{array}$ & $57 \pm 14$ & $57 \pm 12$ & 0.790 \\
\hline MAP (mmHg) & $100.6 \pm 11.8$ & $96.6 \pm 9.3$ & $<.001$ \\
\hline
\end{tabular}

BP: Blood pressure. MAP: Mean arterial pressure.

ROC curve analysis was performed to evaluate of MAP and DAP for prediction of inadequate CCD. At the cut-off value of $>99,8 \mathrm{mmHg}$, sensitivity and specificity of MAP were $57 \%$ and $69 \%$, respectively. At the cut-off value of $>79.5 \mathrm{mmHg}$, sensitivity and specificity of DBP were $72 \%$ and $42 \%$, respectively (Figure 1).
Figure 1. ROC curve analysis of MAP and DAP for prediction of inadequate CDD.

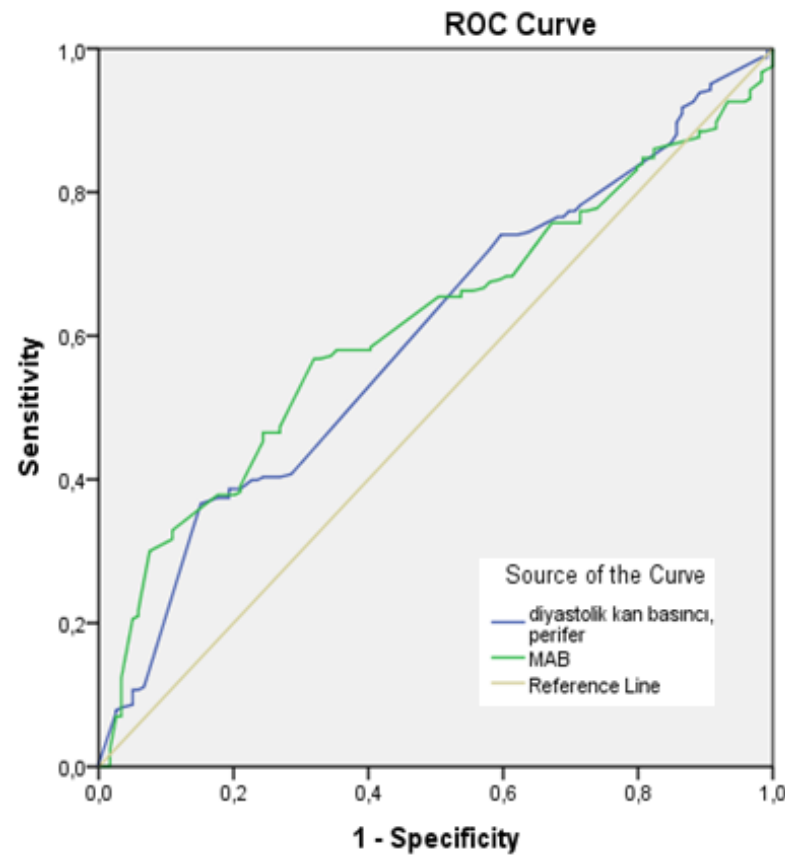

At the cut-off value of $>99,8 \mathrm{mmHg}$, sensitivity and specificity of MAP were $57 \%$ and $69 \%$, respectively ( $\mathrm{AUC}=0.614,95 \% \mathrm{CI}, 0.556-0.673$ ). At the cut-off value of $>79.5 \mathrm{mmHg}$, sensitivity and specificity of DAP were $72 \%$ and $42 \%$, respectively (AUC $=0.599,95 \%$ CI, 0.539-0.660). AUC: area under the curve, CI: Confidence interval.

\section{Discussion}

In our study, we found that peripheral arterial diastolic blood pressure and mean arterial blood pressure were lower in patients with adequate coronary collateral arteries than in inadequate CAD. Previous studies have shown that coronary collateral circulation reduces mortality and reduces infarct size [21]. As you know the relationship between SBP or DBP and cardiovascular disease is well documented [22]. In this line with, high SBP values lead to atherosclerosis by inducing stiffness in the arterial wall and making changes in the vascular structure; low DBP causes weak coronary flow reserve and thus poor myocardial coronary perfusion [23]. Our study 
in which we found significant associations between coronary collaterals, peripheral MAP and diastolic blood pressure, has some similarities with the study of Ege et al [24] which compared central diastolic blood pressure values with collaterals. Central blood pressure measurements are not practical in daily use, and in this sense, it is important to show the relationship between peripheral blood pressure values and collaterals [24]. While increases in SBP contribute to the increase in left ventricular pressure and cause increase in oxygen damage; decrease in DBP can cause coronary perfusion and oxygenation [25]. In the study of Ege et al. [24] the decrease in DBP was interpreted as an important stimulus for angiogenesis. SBP has a minimal effect on coronary perfusion in the presence of fix stenosis because most of the coronary perfusion is in the diastole. Besides, it stimulates arteriogenesis of increased shear stress caused by high SBP; the basic stimulus for angiogenesis is hypoxia [24]. MAP, which is predominantly dependent on cardiac output and systemic vascular resistance, has been identified as the best correlated predictor of body mass index (BMI) and waist circumference (WC) in the study of Kurtoglu et al. [26]. In some studies we can see patients that systolic pressure is normal but diastolic pressure is high or diastolic pressure normal but systolic pressure is high. MAP may be more useful in evaluating such patients [26]. Sesso and colleagues found that the observed MAP in young men was strongly associated with increased cardiovascular risk with SBP and DBP [22]. In studies related with pregnancies, it was determined that MAP, which is seen in 1 st and 2 nd trimester, is a stronger predictor of other blood pressure parameters in preeclampsia. In clinical practice, the importance of predicting the MAP calculation during the first antenatal visit has been emphasized [27].

In the study of children with ambulatory monitoring, the patients were divided into groups with and without the MAP; detection of hypertensive individuals increased by $19 \%$ if MAP was included. This increase is interpreted as a risk factor for early diagnosis in systolic / diastolic hypertension in children with normal or borderline high SBP / DBP [28]. Another study in children, Escape Trial, evaluated the target blood pressure using the MAP: $<50$ percent of children with chronic renal failure had a significantly better kidney survival than those with 50-95 percentile, and the prognostic significance of MAP was noted [29].

In the meta-analysis performed by Miura and his colleagues in the Japanese population [30], the risk of stroke and myocardial infarction were examined with four blood pressure indexes (MAP, PP, SBP, DBP). For stroke and myocardial infarction, MAP was identified as the strongest predictor of risk with SBP, and emphasis was placed on the use of MAP in hypertension guidelines for diagnosis and treatment [30].

Considering the limitations of our study, it is a single centered and retrospective study. On the other hand, the study only involved patients with stable coronary artery disease, more studies involving all patient groups are needed to generalize the findings to all coronary patients.

As a result, peripheral blood pressure measurement is easy and repeatable in daily practice. Daily blood pressure measurements may become more important in the identification and follow-up of high-risk patients, especially since it is easier to calculate MAP values that provide tissue feeding and diastolic blood pressure is more important in young patient than in older 
patients. Therefore, there is a need for a wider range of randomized studies in order to scan and follow coronary artery disease with simple blood pressure arterial measurement.

\section{Conflict of Interest: No conflict of interest was} declared by the authors.

Funding sources: None

\section{References}

[1]Hirai T, Fujita M, Sasayama S, Ohno A, Yamanishi K, Nakajima $H$, et al. Importance of coronary collateral circulation for kinetics of serum creatine kinase in acute myocardial infarction. Am J Cardiol. 1987;60(7):446-50.

[2]Habib GB, Heibig J, Forman SA, Brown BG, Roberts R, Terrin ML, et al. Influence of coronary collateral vessels on myocardial infarct size in humans. Results of phase I thrombolysis in myocardial infarction (TIMI) trial. The TIMI Investigators. Circulation. 1991;83(3):739-46.

[3]Sabia PJ, Powers ER, Ragosta M, Sarembock IJ, Burwell LR, Kaul S. An association between collateral blood flow and myocardial viability in patients with recent myocardial infarction. N Engl J Med. 1992;327(26):1825-31.

[4]Clements IP, Christian TF, Higano ST, Gibbons RJ, Gersh BJ. Residual flow to the infarct zone as a determinant of infarct size after direct angioplasty. Circulation. 1993;88(4 Pt 1):1527-33.

[5] Elsman P, van 't Hof AW, de Boer MJ, Hoorntje JC, Suryapranata H, Dambrink $\mathrm{JH}$, et al; Zwolle Myocardial Infarction Study Group. Role of collateral circulation in the acute phase of ST-segment-elevation myocardial infarction treated with primary coronary intervention. Eur Heart $\mathrm{J}$. 2004;25(10):854-58.
[6]Hirai T, Fujita M, Nakajima H, Asanoi H, Yamanishi K, Ohno A, et al. Importance of collateral circulation for prevention of left ventricular aneurysm formation in acute myocardial infarction. Circulation. 1989;79(4):791-6.7.

[7]Ishihara M, Inoue I, Kawagoe T, Shimatani Y, Kurisu S, Hata T, et al. Comparison of the cardioprotective effect of prodromal angina pectoris and collateral circulation in patients with a first anterior wall acute myocardial infarction. Am J Cardiol. 2005;95(5):622-25.

[8]Rentrop KP, Cohen M, Blanke H, Phillips RA. Changes in collateral channel filling immediately after controlled coronary artery occlusion by an angioplasty balloon in human subjects. J Am Coll Cardiol. 1985;5(3):587-92.

[9]Fujita M, Nakae I, Kihara Y, Hasegawa K, Nohara R, Ueda K, Tamaki S, Otsuka K, Sasayama S. Determinants of collateral development in patients with acute myocardial infarction. Clin Cardiol. 1999;22(9):595-99.

[10]Lembo G, Morisco C, Lanni F, Barbato E, Vecchione C, Fratta L, Trimarco B. Systemic hypertension and coronary artery disease: the link. Am J Cardiol. 1998;82(3A):2H-7H.

[11] Nichols WW, Nicolini FA, Pepine CJ. Determinants of isolated systolic hypertension in the elderly. J Hypertens Suppl. 1992;10(6):S73-7.

[12]Lamia B, Chemla D, Richard C, Teboul JL. Clinical review: interpretation of arterial pressure wave in shock states. Crit Care. 2005;9(6):601-6.

[13] Nichols WW, O'Rourke MF. Aortic pulse wave velocity, reflection site distance, and augmentation index. Hypertension. 2009; 53(1): e9; author reply e10. 
[14]Benetos A, Safar M, Rudnichi A, Smulyan H, Richard JL, Ducimetieère P, Guize L. Pulse pressure: a predictor of long-term cardiovascular mortality in a French male population.

Hypertension. 1997;30(6):1410-5.

[15]Domanski MJ, Davis BR, Pfeffer MA, Kastantin M, Mitchell GF. Isolated systolic hypertension : prognostic information provided by pulse pressure. Hypertension. 1999;34(3):375-80.

[16]Dyer AR, Stamler J, Shekelle RB, Schoenberger JA, Stamler R, Shekelle S, et al. Pulse pressure-III. Prognostic significance in four Chicago epidemiologic studies. J Chronic Dis. 1982;35(4):283-94.

[17]Dellinger RP, Carlet JM, Masur H, Gerlach H, Calandra T, Cohen J, et al. Surviving Sepsis Campaign Management Guidelines Committee. Surviving Sepsis Campaign guidelines for management of severe sepsis and septic shock. Crit Care Med. 2004;32(3):858-73.

[18]Bourgoin A, Leone M, Delmas A, Garnier $\mathrm{F}$, Albanèse $\mathrm{J}$, Martin $\mathrm{C}$. Increasing mean arterial pressure in patients with septic shock: effects on oxygen variables and renal function. Crit Care Med. 2005;33(4):78086.

[19]Benetos A, Thomas F, Bean K, Gautier S, Smulyan H, Guize L. Prognostic value of systolic and diastolic blood pressure in treated hypertensive men: clarification. Arch Intern Med. 2003;163(1):121.

[20]Gensini GG. A more meaningful scoring system for determining the severity of coronary heart disease. Am J Cardiol. 1983;51(3):606.

[21] Meier P, Gloekler S, Zbinden R, Beckh S, de Marchi SF, Zbinden S, etal. Beneficial effect of recruitable collaterals: a 10-year follow-up study in patients with stable coronary artery disease undergoing quantitative collateral measurements. Circulation. 2007;116(9):975-83.

[22] Sesso HD, Stampfer MJ, Rosner B, Hennekens CH, Gaziano JM, Manson JE, Glynn RJ. Systolic and diastolic blood pressure, pulse pressure, and mean arterial pressure as predictors of cardiovascular disease risk in Men. Hypertension. 2000;36(5):801-7.

[23] Cruickshank JM. Coronary flow reserve and the $\mathrm{J}$ curve relation between diastolic blood pressure and myocardial infarction. BMJ. 1988;297(6658):1227-30.

[24]Ege MR, Zorlu A, Yilmaz MB, Acikgoz S, Tandogan I, Cinar Z. Central diastolic blood pressure is associated with the degree of coronary collateral development. Angiology. 2013;64(7):546-52.

[25]Franklin SS, Gustin W 4th, Wong ND, Larson MG, Weber MA, Kannel WB, et al. Hemodynamic patterns of age-related changes in blood pressure. The Framingham Heart Study. Circulation. 1997;96(1):308-15.

[26] Kurtoglu E, Balta S, Sincer I, Altas Y, Atas $\mathrm{H}$, Yilmaz M, et al. Comparision of effects of rosuvastatin versus atorvastatin treatment on plasma levels of asymmetric dimethylarginine in patients with hyperlipidemia having coronary artery disease. Angiology. 2014;65(9):788-93.

[27] Cnossen JS, Vollebregt KC, de Vrieze N, ter Riet G, Mol BW, Franx A, et al. Accuracy of mean arterial pressure and blood pressure measurements in predicting pre-eclampsia: systematic review and metaanalysis. BMJ. 2008;336(7653):1117-20.

[28] Suláková T, Feber J. Should mean arterial pressure be included in the definition of ambulatory hypertension in children? Pediatr Nephrol. 2013;28(7):1105-12. 
[29]ESCAPE Trial Group, Wühl E, Trivelli A, Picca S, Litwin M, Peco-Antic A, Zurowska A, et al. Strict blood-pressure control and progression of renalfailure in children. $\mathrm{N}$ Engl J Med. 2009;361(17):1639-50.

[30] Miura K, Nakagawa H, Ohashi Y, Harada A, Taguri M, Kushiro $\mathrm{T}$, et al. Japan Arteriosclerosis Longitudinal Study (JALS) Group. Four blood pressure indexes and the risk of stroke and myocardial infarction in Japanese men and women: a meta-analysis of 16 cohort studies. Circulation. 2009;119(14):1892-98. 